\title{
BIBLIOGRAFÍA GENERAL
}

Ahumada, R. (1975). "Seminario de teatro argentino (mímeo). Apuntes de Cátedra": Facultad de Letras de la Universidad Católica de Santa Fe.

Altman, R. (2000). Los géneros cinematográficos. Barcelona: Paidós.

Amar Sánchez, A. (1992). "El género de no ficción: un campo problemático" en El relato de los hechos. Rodolfo Walsh: testimonio y escritura. Rosario: Beatriz Viterbo. Arfuch, L. (2002). El espacio biográfico. Dilemas de la subjetividad contemporánea. Buenos Aires: Fondo de Cultura Económica.

Aristóteles (1973). Poética. Buenos Aires: Losada.

Arnoux, E. y otros (1989). Elementos de semiología y análisis del discurso. Buenos Aires: UBA/Cursos Universitarios.

Aróstegui, J. (1995). La investigación histórica: teoría y método. Barcelona: Crítica. Augé, M. (1998). La guerra de los sueños. Barcelona: Gedisa.

Aumont, J. et al (1989). Estética del cine. Espacio fílmico, montaje, narración, lenguaje. Barcelona: Paidós.

Aumont, J. y Marie, M. (1990). Análisis del film. Barcelona: Paidós.

Austin, J. L. (1982). Cómo hacer cosas con palabras. Barcelona: Paidós.

Bajtin, M. (1982). Estética de la creación verbal. México: Siglo XXI.

__ (1989). "Los procedimientos del discurso narrativo" en Teoría y estética de la novela. Madrid: Taurus.

Bal, M. (1998). Teoría de la narrativa. Una introducción a la narratología. Madrid: Cátedra.

Barbero, J. M. y Rey G. (1999). Los ejercicios del ver. Hegemonía audiovisual y ficción televisiva. Barcelona: Gedisa.

Barthes, R. (1980). S/Z. Buenos Aires: S XXI.

Barthes, R. (1970). "El discurso de la historia" en Estructuralismo y lingüística. Buenos Aires: Nueva visión. 
(1973). Sémiotique narrative et textuelle. Larousse: Paris.

(1974). "Análisis estructural del relato" en Comunicaciones / 8. Buenos Aires: Tiempo Contemporáneo.

— (1976). El grado cero de la escritura. Buenos Aires: Siglo XXI.

- (1977). Ensayos críticos. Barcelona: Seix Barral.

(1984). El susurro del lenguaje. Buenos Aires: Paidós Comunicación.

Benveniste, E. (1982). Problemas de Lingüística General, I. México: Siglo XXI. (1985). Problemas de Lingüística General, II. México: Siglo XXI.

Bernárdez, E. (1982). Introducción a la lingüística del texto. Madrid: Espasa Calpe. Bettendorff, M. E. \& Prestigiacomo, M. R. (1997). La ventana discreta. Introducción a la narrativa filmica. Buenos Aires: Atuel.

Bettetini, G. (1986). La conversación audiovisual. Problemas de la enunciación fílmica y televisiva. Madrid: Cátedra.

Bordwell, D. (1995). El significado del filme. Buenos Aires: Paidós.

Bourdieu, P. (1990). The logic of practice. Cambridge: Polity Press.

Boves Naves, C. (1989). "La investigación semiológica" en La semiología. Madrid: Síntesis.

(1993). La novela. Madrid: Síntesis.

(1997). Semiótica de la escena. Madrid: Arco Libros.

Bruner, J. (1986). Actual minds, possible worlds. Cambridge: Harvard University Press.

- (1991). Actos de significado: más allá de la revolución cognitiva. Madrid: Alianza. (1997). La educación, puerta de la cultura. Madrid: Visor.

Buxó, Ma. J. y de Miguel, J. M. [edits.] (1999). De la investigación audiovisual. Barcelona: Proyecto .A. Eds.

Calabrese, E. (1994). "Historias, versiones y contramemorias en la novela argentina actual" en Itinerarios entre la ficción y la historia (comp.). Buenos Aires: Grupo editor Latinoamericano.

Camillioni, A. (1997). Los obstáculos epistemológicos en la enseñanza. Barcelona: Gedisa.

(1994). "Epistemología de la didáctica de las ciencias sociales" en Aisenberg, B. y Alderoqui S. (1994). Didáctica de las Ciencias Sociales. Aportes y Reflexiones. Buenos Aires: Paidós. 
Camilloni, A.; Davini, M- C; Edelstein, G. y otras (1996). Corrientes didácticas contemporáneas. Buenos Aires: Paidós.

Canal Feijoo, B. (1952). Burla, credo, culpa en la creación anónima: sociología, etnología y psicología en el folklore. Santiago del Estero: Ediciones Biblioteca Nacional. Carmona, R. (1993). Cómo se comenta un texto fílmico.Madrid: Cátedra.

Carr, D. (1986). Time, narrative and history. Bloomington: Indiana University Press. Casetti, F. (1989). El film y su espectador. Madrid: Cátedra. (2000). Teorías del cine (1945-1990). Madrid: Cátedra.

Casetti, F. y Di Chio, F. (1991). Cómo analizar un film. Barcelona: Paidós.

Cattrysse, P. (1996). "Descriptive and normative norms in film adaptation: the Hays Office and the American Film Noir" en Cinémas / 6.

_ (1997). "Audiovisual Translation and New Media" en Hodgson-Soukup (Ed.) Medium to another. Basic Issues for communicating the Scriptures. Media Kansas City \& New York: Sheed and Ward and American Bible Society.

Caudana, C. (1991). "Escritura del texto y textualidad de la imagen" en Literatura y espectáculo. Santa Fe: UNL/CyT.

— (1997a). "Para una morfología del discurso didáctico" en Cuadernos de la forma. Buenos Aires: Sociedad de Estudios Morfológicos de la Argentina. №1, págs. 63-74. __ (1997b). "Sobre semiótica y educación. Saberes y dominios" en Decir, hacer, enseñar. Semiótica y pragmática discursiva. Santa Fe: UNL/CyT.

- (1998). Sobre textos y discursos en las construcciones del sentido. Temas de Humanidades / 3. Santa Fe: UNL/CESIL.

- (1999). La construcción del relato como objeto de la historia. Documentos de Trabajo /PEIHS, 12. Santa Fe: UNL.

- (2002). "La semiosis didáctica (constituciones, formatos y soportes)" en Texturas, 2. Santa Fe: UNL.

_ (2003). "Discursividades, texturas... polémicas en la historia" en Texturas, 3. Santa Fe: UNL.

- (2004). "Travesías del documental" en De signos y sentidos / 1. Santa Fe: Ediciones UNL.

- (2005). "Construcción de proyectos en investigaciones aplicadas" en De signos y sentidos / 3. Santa Fe: Ediciones UNL. 
(2007). "Intersemiosis narrativas y transfiguraciones textuales", en De signos y sentidos - Cuadernos del proyecto, Año 3, № 5, marzo de 2007. Santa Fe: Ediciones UNL.

Cea D'Ancona, M. de los A. (1996). Metodología cuantitativa: estrategias y técnicas de investigación social. Madrid: Síntesis.

Chartier, R. (1996). Escribir las prácticas. Buenos Aires: Manantial.

- (1998). "La historia entre representación y construcción", en Prismas. Revista de Historia intelectual, 2. UNQ, Setiembre.

Chion, M. (1990). La audiovisión. Introducción a un análisis conjunto de la imagen y el sonido. Barcelona: Paidós.

Contursi, M. y Ferro, F. (2000). La narración. Usos y teorías. Buenos Aires: Norma. De Alba, A. (1994). Currículum: crisis, mito y perspectivas. México: Universidad Nacional.

De Certeau, M. (1975). L'ecriturede l'histoire. Paris: Gallimard. (1995). Historia y psicoanálisis entre ciencia y ficción. México: Universidad Iberoamericana.

De Toro, F. (1987). Semiótica del teatro. Del texto a la puesta en escena. Buenos Aires: Galerna.

Debord, G. (1967). La sociéte du spectacle. París: Buchet-Chatel.

Del Coto, Ma. R. (1995). De los códigos a los discursos. Una aproximación a los lenguajes contemporáneos. Buenos Aires: Docencia.

Deleuze, G. (1987). La imagen-tiempo. Estudios sobre cine (tomos 1 y 2). Barcelona: Paidós.

Descombes (1977). L'inconscient malgré lui. París, Minuit, por Rosa, R. (1990): El arte del olvido. Buenos Aires: Puntosur.

Dewey, J. (1938). Experience and education. New York: Collier Books.

Díaz Barriga, A. (1994). El docente y los programas escolares. Lo institucional y lo didáctico. Colección Educación superior en América Latina.

Dölezel, L. (1990). Poetica occidentale. Torino: Einaudi.

Dorra, R. (1990). "Perspectiva de la semiótica” en Greimas, A. J. De la imperfección. México: FCE.

Dubatti, J. (2009). El teatro teatral. Nuevas orientaciones en Teatrología. Bahía Blanca: Editorial de la Universidad Nacional del Sur. 
Ducrot, O. (1984). El decir y lo dicho. Buenos Aires: Hachette.

Duran, G. (1982). "Sémiologie et relations dans le champ du spectaculaire" en Degrés, 29, Bruselas.

Eco, U. (1976). Tratado de semiótica general. Barcelona: Lumen.

— (1981). "El lector modelo" y "Niveles de cooperación textual" en Lector in fabula. Barcelona: Lumen.

- (1986). De los espejos y otros ensayos. Barcelona: Lumen.

- (1994). Signo. Barcelona, Labor.

(1996). Seis paseos por los bosques narrativos. Barcelona: Lumen.

Edeleman, M. (1991). La construcción del espectáculo político. Buenos Aires: Manantial.

Eisner, E. (1982). Cognition and curriculum. New York: Longman.

- (1988). "The primacy of experience and the politics of method" en Educational Researcher, $\mathrm{N}^{\circ} 17(5)$.

_ (1998). El ojo ilustrado. Indagación cualitativa y mejora de la práctica educativa.Buenos Aires: Paidós.

Elbaz, F. (1988). Knowledge and dicourse. The evolution of research on teacher thinking.UK: Nottingham University Press.

Even-Zohar, I. (1978). Papers in Historical Poetics, Tel Aviv (traducción FH de la UNSa).

Fernández Diez, F. y Martínez Abadía, J. (1999). Manual básico de lenguaje y narrativa audiovisual. Barcelona: Paidós.

Fernández Pedemonte, D. (1996). La producción del sentido en el discurso poético. Buenos Aires: Edicial.

Ferro, R. (1996). "Más allá de la ficción", en SyC, 7. Buenos Aires.

Filmus, D.; Ibarrola, M.; Aguerrondo, I.; Padua y otros (1991). Propuesta educativa (publicación de la FLACSO), Año 3, Nro. 5, Buenos Aires: Miño y Dávila.

Ford, A. (1999). La marca de la bestia. Identificación, desigualdades e infoentretenimiento. Buenos Aires: Norma.

Foucault, M. (1987). El orden del discurso. Barcelona: Tusques.

García Berrio, A. (1979). Lingüística del texto y crítica literaria. Madrid: Alberto Corazón.

García Jiménez, J. (1996). Narrativa audiovisual. Madrid: Cátedra.

Garrido Domínguez, A. (1996). El texto narrativo. Madrid: Síntesis. 
Gaudreault, A. y Jost, F. (1995). El relato cinematográfico. Cine y narratología. Barcelona: Paidós.

Genette, G. (1972). Figuras III. Barcelona: Lumen. (1988). Palimpsestos. La literatura en segundo grado. Madrid: Taurus. (1998). Nuevo discurso del relato. Madrid: Cátedra.

Gimeno Sacristán, J. (1991). El currículum: una reflexión sobre la práctica. Madrid: Morata.

Goldman, N. (1989). El discurso como objeto de la historia. Buenos Aires: Hachette González Requena, J. (1980). "Film-texto. Semiótica" en Contracampo. Año 2, No 3. Madrid.

(1992). El discurso televisivo: espectáculo de la postmodernidad. Madrid: Cátedra.

—_ [comp.] (1995). El análisis cinematográfico. Teoría y práctica del análisis de la secuencia. Madrid: Editorial Complutense.

Goodson, I. (1988). Teachers life stories and studies of curriculum. Collected Essays, London, New York and Philadelphia: Falmer.

Greimas, A. (1976). Sémiotique et sciences sociales. París: Du Seuil.

- (1983). La semiótica del texto. Barcelona: Paidós.

(1989). Del sentido II. Ensayos semióticos. Madrid: Gredos.

(1990). De la imperfección. México:FCE.

Greimas, A. y Courtés, J. (1982; 1991). Semiótica. Diccionario razonado de la teoría del lenguaje, I y II. Madrid: Gredos.

Halliday, M. (1982). El lenguaje como semiótica social. México: FCE.

Helbo, A. (1989). Teoría del espectáculo. El paradigma espectacular. Buenos Aires:

Galerna

Hernández Aguilar, G. [comp.] (1994). Figuras y estrategias. En torno a una semiótica de lo visual. México: Siglo XXI.

Hernández Sampieri, R. y otros (1997). Metodología de la investigación. México: Interamericana.

Hjelmslev, L. (1961). Prolegómenos a una teoría del lenguaje. Madrid: Gredos.

Ingarden, R. (1971). At the Foundations of the Theory of Knowledge. Polonia: PWN, Warszawa. 
Jakobson, R. (1975). Ensayos de lingüística general. Barcelona: Ariel.

Jameson, F. (1980). La cárcel del lenguaje. Barcelona: Ariel.

- (1991). Teoría de la posmodernidad. Madrid: Trotta.

Jitrik, N. (1995). Historia e imaginación literaria. Buenos Aires: Biblos.

—_ [comp] (1990). Irrupción del discurso. Interdisciplina y transdisciplinariedad. México: UNAM.

Jofre, M. (1990). "Análisis textual de la diégesis", en Teoría literaria y semiótica. Santiago de Chile: Ed. Universitaria.

- (1995). Tentando vías: semiótica, estudios culturales y teoría de la literatura. Santiago de Chile: Universidad Católica Blas Cañas.

Jost, F. (2002). El ojo-cámara. Entre film y novela. Buenos Aires: Catálogos.

Kerbrat Orecchioni, C. (1986). La enunciación. De la subjetividad en el lenguaje. Buenos Aires: Hachette.

Klimovsky, G. (1995). Las desventuras del conocimiento científico. Buenos Aires: A-Z.

Kristeva, J. (1981). Semiótica I. Madrid: Fundamentos.

LaCapra, D. (1987). History and criticism. New York: Cornell University Press.

- (1998). "Repensar la historia intelectual y leer textos" en Giro lingüístico e historia intelectual (comp.) UNQ.

Lakoff, G. \& Johnson, M. (1980). Metaphors we live by. Chicago: Chicago University Press.

Larrosa, J. (1995). Déjame que te cuente. Ensayos sobre narrativa y educación. Barcelona: Laertes.

Latella, G. (1985). Metodología y teoría semiótica. Buenos Aires: Hachette.

Lavandera, B. (1985). Curso de lingüística para el análisis del discurso. Buenos Aires: Centro Editor de América Latina.

Legendre, P. y otros (1982). El discurso jurídico. Perspectiva psicoanalítica y otros abordajes epistemológicos. Buenos Aires: Hachette.

León, B. (1999). El documental de divulgación científica. Barcelona: Paidós.

Lincoln, Y. \& Guba, E. (1985). Naturalistic inquiry. Newbury Park, CA: Sage Publications. - (1989). Personal communication. Newbury Park, CA: Sage Publications.

Litwin, E. (1995a). Tecnología Educativa. Políticas, historias, propuestas. Buenos Aires: Paidós. 
(1995b). "La investigación en el campo de la didáctica. Cuestiones teóricas y metodológicas" en AA. VV.: El oficio del investigador. Buenos Aires: Homo Sapiens. - (1997). Las configuraciones didácticas. Una nueva agenda para la enseñanza superior. Buenos Aires: Paidós.

Lodge, D. (1990). Narration with words. Cambridge: Cambridge University Press.

Lomas, C. y otros (1993). Ciencias del lenguaje, competencia comunicativa y enseñanza de la lengua. Barcelona: Paidós.

Lotman, I. (1996). La semiosfera, I - II y III. Semiótica de la cultura, del texto... Madrid: Cátedra.

Lozano, J. y otros (1993). Análisis del discurso. Hacia una semiótica de la interacción textual. Madrid: Cátedra.

Macintyre, A. (1966). A short history of ethics. University of Michigan: Macmillan.

\section{_ (1981). Alter virtue. Paris: Notre Dame University Press.}

Maingueneau, D. (1980). Introducción a los métodos de análisis del discurso. Buenos Aires: Hachette.

Mancuso, H. (1999). "Abducción y deducción de hipótesis" en Metodología de la investigación en ciencias sociales. Lineamientos teóricos y prácticos de semioepistemología. Buenos Aires: Paidós.

Marc, E., y Picard, D. (1992). La interacción social. Cultura, instituciones y comunicación. Barcelona: Paidós.

Martínez Bonati, F. (1992). La ficción narrativa. Murcia: Editum.

Martínez García, J. I. (1992). La imaginación jurídica. Madrid: Debate.

McEwan, H. \& Egan, K. (1998). La narrativa en la enseñanza, el aprendizaje y la investigación. Buenos Aires: Amorrortu.

Metz, Ch. (1966). "La gran sintagmática del film narrativo" en Barthes, R. et. al: Revista Comunicaciones / 8, Ed. du Seuil. Ed. Cast, 1972. Buenos Aires: Tiempo contemporáneo.

_ (1972). Ensayos sobre significación en el cine. Buenos Aires: Tiempo contemporáneo.

(1979). Psicoanálisis y cine. El significante imaginario. Barcelona: G. Gili.

Mishler, E.G. (1986). Context and narrative. Cambridge: Harvard University Press.

Mitchell, W.J. (1981). On narrative. Chicago: Chicago University Press. 
Mogni, F. (1963). “Conversación con Lautaro Murúa” en Tiempo de cine, año IV, № 16. Mumby, D. [comp] (1997). Narrativa y control social. Perspectivas críticas. Buenos Aires: Amorrortu.

Munby, H. (1986). "Metaphor in the thinking of teachers: An exploratory Study" en Journal of Curriculum Studies N 18, págs 197-209.

Nichols, B. (1997). La representación de la realidad. Cuestiones y conceptos sobre el documental. Barcelona: Paidós.

O'Sullivan, T. y otros (1997). Conceptos clave en comunicación y estudios culturales. Buenos Aires: Amorrortu.

Pagella, B. (1965). Nuevos temas en el teatro argentino: la influencia europea. Buenos Aires: Huemul.

Palti, E. (1998). Giro lingüístico e historia intelectual. Bernal: U. N. Quilmes.

Pavis, P. (1983). Diccionario del teatro. Dramaturgia, estética, semiología.Barcelona: Paidós.

Polkinghorne, D. E. (1988). Narrative knowing and the human sciences. New York: New York University Press.

Popkewitz, T. (1994). Sociología política de las reformas educativas. Madrid: Morata. Prigogine, I. (1996). El fin de las certidumbres. Santiago de Chile: Andrés Bello.

Ranciere, J. (1993). Los nombres de la historia: una poética del saber. Buenos Aires: Nueva Visión.

Redondo Goicochea, A. (1995). La polifonía textual. Madrid: S. XXI.

Reid, W. (1988). Institutions and Practices. Essays in the Deliberative Tradition. New Jersey: Lawrence Erlbaum Associates Publishers.

Ricoeur, P. (1983-1985). Tiempo y narración. 3 ts. Madrid: Cristiandad

— (1985). Hermenéutica y acción. Buenos Aires: Docencia.

— (1998). Historia y narratividad. Barcelona: Paidós. (2001). Del texto a la acción. Ensayos de hermenéutica II. Buenos Aires: FCE.

Rodas, J.V. y Rodríguez, J. S. (1991). “Aproximación semiótica a la práctica educativa", en Revista argentina de educación, Año 9. Nro. 15, Buenos Aires: AGCE. Rodríguez Gómez, G. y otros (1999). Metodología de la investigación cualitativa. Málaga: Aljibe.

Rodríguez Illera, J. L. (comp.) (1988). Educación y comunicación. Barcelona: Paidós. 
Rosa, N. (1990). "Los fantasmas de la crítica" en El arte del olvido. Buenos Aires: Puntosur.

Saer, J. J. (1999). La narración-objeto. Buenos Aires: Planeta-Seix Barral.

Sarbin, R. (1986). The storied nature of human conduct. New York: Praeger Publishers.

Sazbón, J. (1998). “La nueva filosofía de la historia. Una sinopsis" en Prismas. Revista de Historia intelectual, 2. UNQ, Septiembre.

Schnitman, D. (comp.) (1994). Nuevos paradigmas, cultura y subjetividad. Buenos Aires: Paidos.

Shön, D. (1987). Educating the reflective practitioner. San Francisco: Jossey-Bass Higher Education.

Shulman, L.S. (1987). Knowledge and teaching.Foundations of the new reform. Cambridge: Harvard University Press.

— (1989). "Paradigmas y programas de investigación en el estudio de la enseñanza: Una perspectiva contemporánea" en Wittrock, M. La investigación en la enseñanza. Tomo I. Barcelona: Paidos.

Stam, R. (1999). Nuevos conceptos de la teoría del cine. Barcelona: Paidós.

Steimberg, O. (1993). Semiótica de los medios masivos. Buenos Aires: Atuel.

Stone, L. (1979). "The revival of narrative: reflections on a new old history" en Past \& Present No 85. UK: Oxford University Press. págs. 3-24.

Tassara, M. (2001). El castillo de Borgonio. La producción de sentido en el cine. Buenos Aires: Atuel.

Todorov, T. (1971). Literatura y significación. Barcelona: Planeta.

Torop, P. (2002). "Intersemiosis y traducción intersemiótica" en Revista Cuicuilco / 9(25). México: Escuela Nacional de Antropología e Historia.

Torre Nilsson, L. (1985). "Los creadores de argumentos" en Torre Nilsson por Torre Nilsson. Buenos Aires: Editorial Fraterna.

Traversa, O. (1984). Cine: el significante negado. Buenos Aires: Hachette.

Ubersfeld, A. (1989). Semiótica teatral. Madrid: Cátedra.

Usandizaga, H. (1993). "Semiótica y teorías de la literatura" en El enfoque comunicativo de la enseñanza de la lengua. Barcelona: Paidós.

Van Dijk, T. (1990). La noticia como discurso. Barcelona: Paidós.

Van Maanem, J. (1988). On writing ethnography. Chicago: Chicago University Press. 
Verón, E. (1978). "Semiosis de l'ideologuique et du pouvoir", Communications, 28, París: Du Seuil; traducción en Espacios, 1, Buenos Aires, 1984.

(1987). La semiosis social. Fragmentos de una teoría de la discursividad. Barcelona: Gedisa.

Verón, E. y otros (1987). El discurso político. Lenguajes y acontecimientos. Buenos Aires: Hachette.

Veyne, P. (1984). Cómo se escribe la historia. Madrid: Alianza.

Vignaux, G. (1986). La argumentación. Ensayo de lógica discursiva. Buenos Aires: Hachette.

Vilches, L. (1998). La lectura de la imagen. Prensa, cine, televisión. Barcelona: Paidós.

White, H. (1976). "The fiction of factual representation" en The Literature of Fact ed. AngusFletcher.New York: Columbia University Press.

(1992a). Metahistoria: la imaginación histórica en la Europa del siglo XIX. México: FCE.

—_ (1992b). El contenido de la forma. Narrativa, discurso y representación histórica. Barcelona: Paidós.

Zunzunegui, S. (1995). Pensar la imagen. Madrid: Cátedra. (1996). La mirada cercana. Microanálisis fílmico. Barcelona: Paidós. 
